\title{
Management of Anterior Diastema Using Direct Adhesive Technique
}

Emna Hidoussi Sakly ${ }^{1 *}$, Hana Sarraj ${ }^{1}$, Neila Zokkar $^{2}$

\author{
${ }^{1}$ Assistant professor, University of Monastir, Faculty of Dental Medicine of Monastir, Department of Restorative Dentistry- \\ Endodontics, Research Laboratory of Oral Health and Rehabilitation LR 12ES11, Monastir 5000, Tunisia \\ ${ }^{2}$ Professor, University of Monastir, Faculty of Dental Medicine of Monastir, Department of Restorative Dentistry-Endodontics, \\ Research Laboratory of Oral Health and Rehabilitation LR 12ES11, Monastir 5000, Tunisia
}

\begin{abstract}
Article History
Received: 18.09 .2020

Accepted: 05.10.2020

Published: 10.10 .2020

Journal homepage:

Abstract: Residual diastema closure treatment is popular treatment in esthetic dentistry. Indeed these median anterior diastems can compromise the harmony of a patient's smile. Thinks to the advances in the field of adhesive dentistry, practioners can use direct composite restoration to solve these situations. This restorative approach is simple, fast, predictable and less expensive than indirect restorations. It present many adventages such us conservative and esthetic treatment, adequate interproximal contact establishment, an esthetic emergence profile with parodontal papilla respect. In this article, we will describe, through clinical cases, the closure of diastema inter incisor by direct composite resin.
\end{abstract}

https://www.easpublisher.com/easjdom

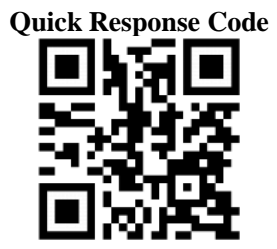

Keywords: Diastema, Composite resin, Anterior teeth.

Copyright (C) 2020 The Author(s): This is an open-access article distributed under the terms of the Creative Commons Attribution license which permits unrestricted use, distribution, and reproduction in any medium for non commercial use (NonCommercial, or CC-BY-NC) provided the original author and source are credited.

\section{INTRODUCTION}

Tooth diastemas are gaps or spaces between two adjacent teeth in the same tooth arch and it is of common occurrence in general population. They manifest spaces of more than $0.5 \mathrm{~mm}$ between the proximal surfaces of adjacent teeth and they show multifactorial aethiology [1]. The presence of an anterior diastema or multiple diastemas in adults can cause an aesthetic damage to the smile and facial harmony [1, 2]. Usually, these diastemas can be managed effectively with an orthodontic treatment. Often considered the treatment of choice, this solution may however be not sufficient to resolve the cosmetic defect, especially in cases where the diastema is associated with a dental malformation, which requires the use of additional procedures. In these cases, a restorative procedure is needed. To obtain positive outcomes, there is currently a trend within the restorative dentistry to develop faster and less invasive procedures. Direct Composite resin restoration can provide excellent results based on the biological, functional, and esthetic aspects of the closure of the interdental spaces. These results are mainly due to the development of the adhesive techniques and compositions of these systems, as well as the improvement of composite resin materials. Due to the development of the adhesive techniques and compositions of composite resin, practitioners can treat these situations and obtain a satisfactory aesthetic result with a restoration that mimics the natural tooth structure. Indeed, recent aesthetic composite resin materials have similar physical and mechanical properties to that of the natural tooth and possess an appearance like the natural dentin and enamel [2]. They offer an expanded range of shades and varying opacities designed specifically for layering technique whereas early brands of composite resins offered only "body" shades and appeared dull and dense [2]. Currently, the use of materials employing nanotechnology in their development has been an option for aesthetic restorations. Composite resin is an ideal material when restoring diastema closure. It is considered a noninvasive, rapid and less expensive therapeutic alternative for the patient. It is highly polishable, long lasting and mimics natural tooth structure [3]. It is indicated when the malposition and the forward inclination of the anterior teeth are sufficiently moderate not to compromise the obtention of a satisfactory result, viewable to an analogous or digital aesthetic project. Depending on the clinical and aesthetic situation, the diastemas will be closed either on one side (unilateral technique) or on both sides (bilateral technique). The choice of techniques depends mainly on the aesthetic requirements of the given situation. Central diastemas generally need to be closed 
starting from two collateral teeth for reasons of symmetry, lateral diastemas can often be treated with satisfaction using a unilateral technique [6]. Silicone guide can facilitate the stratification technique of composite resin on anterior teeth. It can reproduce the palatal anatomy of fractured anterior teeth, as well as reconstruct the occlusion guides [9] and conoid lateral incisors, and close diastemas [4].

Thus, the aim of this study is to report, through a clinical case, the stratification technique of composite resins in the restorative treatment of the closure of anterior diastemas.

\section{Clinical Case}

A 25-year-old female patient was referred to the Department of Restorative Dentistry at Dental Clinic of Monastir for the closure of anterior diastema between 12 and 13, after ending the orthodontic treatment. Patient's medical history did not reveal any systemic diseases and intraoral examination revealed the presence of a morphological abnormality of the right maxillary lateral incisor. The 12 presented the conoid morphology (Figure-1).

Because the diastema was small, that is, less than $2 \mathrm{~mm}$ (Figure-2), we opted for the restoration of the teeth employing the direct restorative adhesive system with composite resin.

The teeth were submitted to prophylaxis by pumice and water, and the selection of dentin and enamel shades was performed.to avoid hydric contamination and enhance the visibility of the treatment site, we placed a rubber dam, kept in place with the aid of orthodontic elastic rubber bands to obtain a gingival displacement from the incisors. Then, buccal and proximal surfaces of 12 were prepared with a small diamond granulometry bur in order to remove the superficial hyper mineralized layer of enamel (Figure-2). This step allows to optimize an adhesive procedure. The enamel surfaces were etched by orthphosphoric acid of $37 \%$ for 30 seconds. After that, the surface was dried by absorbent paper and the bonding agent was applied (Futurabond $\mathrm{M}+$, VOCO) by using a regularsize microbrush and a light-curing was performed according to the manufacturer's instructions. The palatal and interproximal surfaces were restoreded with a hybrid composite (Polofil NHT VOCO) by using a silicone guide. A thin layer of translucent shade of the resin was used palatinally as enamel (Figure-4). An increment of the A2D shade was applied, leaving a space in the incisal surface to characterize this tooth area. A single layer of the A2Eshade was applied onto the labial surface using the technique of «Natural layering concept ». Each portion of the composite resin was light-cured through a LED device for the time recommended by the manufacturer. Immediately after the removal of the rubber dam (Figure-5, the finishing restoration was carried out with polishing discs (Ultra Gloss Composite PolishingSystem,Axis,USA) from rough to fine grains by using a low speed handpiece. After 24 hours, the final finishing and polishing were executed. Clinical control was programmed after 1 month (Figure-6).

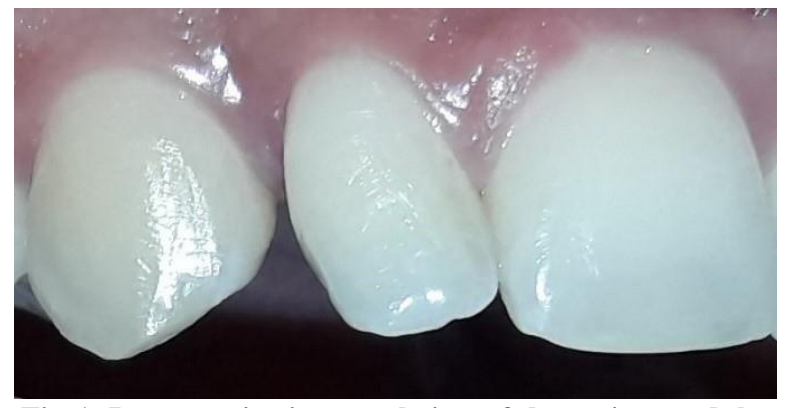

Fig-1: Preoperative intraoral view of the patient and the diastema after orthodontic final treatment

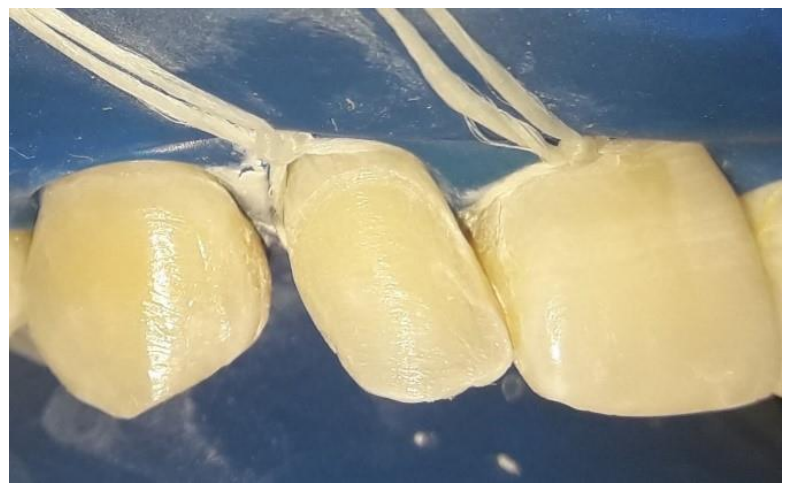

Fig-2: Maxillary anterior teeth were isolated with a rubber dam

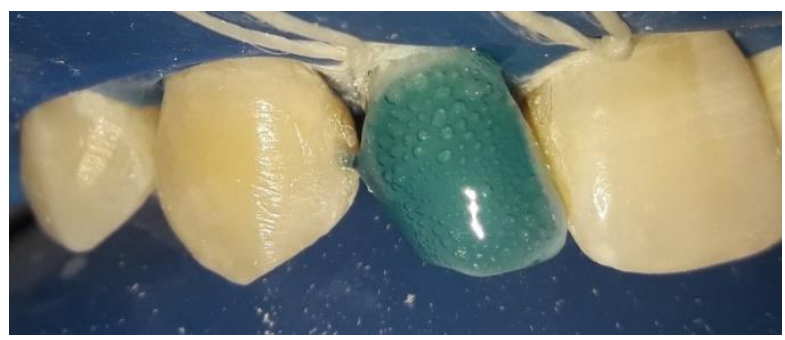

Fig-3: Etching of enamel surfaces

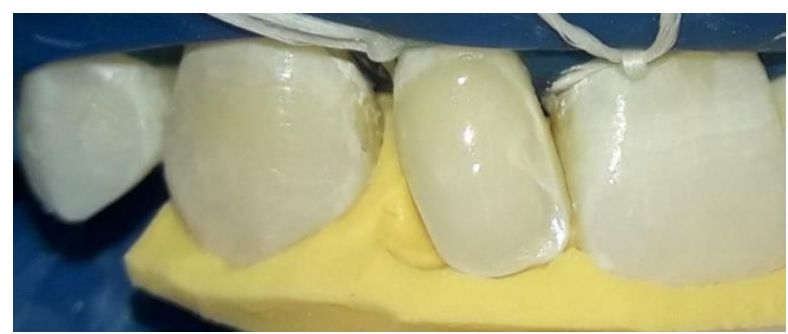

Fig-4: Silicone index put in the mouth 


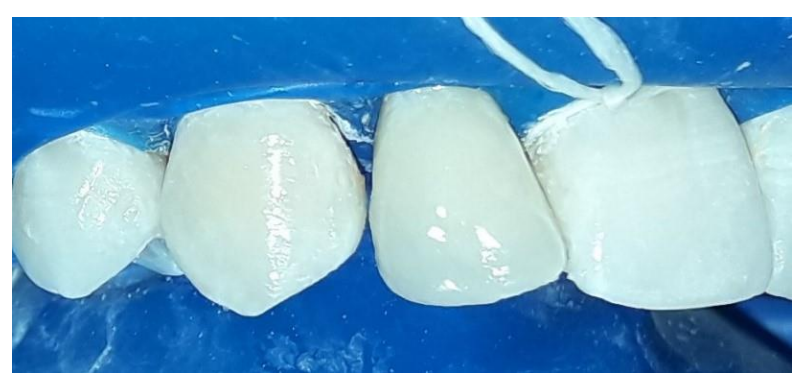

Fig-5: Restoration finishing immediately prior to the removal of the absolute isolation

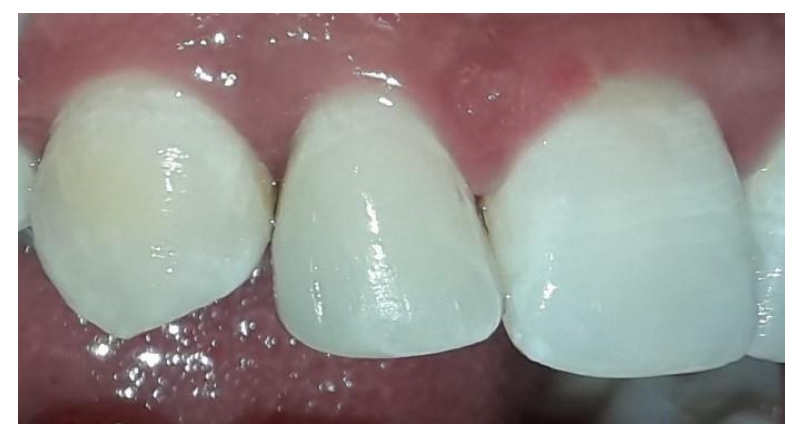

Fig-6: The view of the restoration at 6- month recall

\section{DiscuSSION}

The treatment of diastema requires an adequate diagnosis of its etiology and treatment planning. Diagnoses include radiological and clinical examinations and possibly tooth size evaluation. Several aspects should be considered to achieve good results [1]. In cases such as the one presented here, the evaluation of the diastema size is fundamental for the decision between the direct and indirect treatment. Diastemas may also be due to abnormalities in shape. The teeth can have a "grain of rice" shape and their small size differs from other teeth. Currently, the lateral incisors are more affected. This anomaly results in a crown which is reduced in the mesio-distal direction. The conoid shape of the lateral incisor accentuates the space which becomes too wide to be completely closed by the composite resin using the direct technique

The diastema presented in this reported case can be classified as small, as its size is between 0.5 and $2 \mathrm{~mm}$ and the restorative treatment was chosen.

To enhance colour, form and function in the esthetic zone, the direct restorative procedures with bonded resin composites are considered the most conservative and the least invasive technique.

This restoration offers various advantages, it can be placed in a single visit and it does not involve laboratory fees that escalate costs. The direct adhesive restorative procedures have the advantages of requiring the minimum weariness of tooth structure and showing a good clinical durability. Composite resin is an ideal material when restoring the anterior diastema closure. It is highly polishable, long lasting and mimics natural tooth structure. In this present study, we used nanoparticles composite. The materials with this type of particles provide a smoother surface and therefore favor the outcome after polishing and brushing procedures.

Nanoparticulated composite resins tend to show a smaller brightness loss and a smaller increase of the superficial rugorosity as time goes [4]. However, the creation of perfect direct restorations

It is still difficult because of the imperfect optical properties of composite resins and because of improper clinical procedures.

Procedures which consist in imitating the shades and layering techniques developed for ceramic restorations are complicated and mastered only by highly skilled practioners. Thus, the appearance of the "natural layering concept" made it possible to simplify the procedure and led to achieve a highly aesthetic direct restoration. Since this concept has become a reference in the field of composite restorations, the aim of this paper is to familiarize the practitioner with the features and clinical aspects of this new technique.

The freehand laminating composite resin veneers is based on the "natural layering concept" which is more conservative in terms of dental tissue and is carried out in a single clinical session.

The principle is to use different layers of composites, each one replacing a type of dental tissue.

For our clinical case, the stratification is purely aesthetic: the palatal wall is functional, and therefore, the composite is limited to the vestibular surface and possibly the anterior part of the free edge.

For complex anterior composite restorations the clinician must have a comprehensive understanding of the colour, translucency and morphology of natural teeth as well as of the material sciences and the restorative techniques involved.

\section{CONCLUSION}

With advances in material sciences, dentists can now, more artistically and predictably, mimic natural dentition and closure diastema that are not only fully functional, but also beautiful.

When used correctly, composite resin provides fast, economical and aesthetic results. This method should be seen as a real alternative to the more invasive traditional restorations performed using porcelain crowns and veneers.

\section{ACKNOWLEDGEMENT}

Emna Hidoussi Sakly and Hana Sarraj are contributed equally to this work. 


\section{RÉFÉRENCES}

1. Wolff, D., Kraus, T., Schach, C., Pritsch, M., Mente, J., Staehle, H. J., \& Ding, P. (2010). Recontouring teeth and closing diastemas with direct composite buildups: a clinical evaluation of survival and quality parameters. Journal of dentistry, 38(12), 1001-1009.

2. Rohit, S., Gilsa, K., Priyanka, M., \& Ganesh, T. K. (2014). Esthetic Conservative Management of Interdental spaces using Direct Composite Resin Restorations- A Case Report. Journal of Dental and Medical Sciences. 13(6):109-112.

3. Hwang, S. K., Ha, J. H., Jin, M. U., Kim, S. K., \& Kim, Y. K. (2012). Diastema closure using direct bonding restorations combined with orthodontic treatment: a case report. Restorative dentistry \& endodontics, 37(3), 165-169.

4. Pjetursson, B. E., Sailer, I., Zwahlen, M., \& Hämmerle, C. H. (2007). A systematic review of the survival and complication rates of all-ceramic and metal-ceramic reconstructions after an observation period of at least 3 years. Part I: single crowns. Clinical oral implants research, 18, 7385 .

5. Dietschi, D., \& Fahl, N. (2016). Shading concepts and layering techniques to master direct anterior composite restorations: an update. British dental journal, 221(12), 765-771.

6. Kim, Y. H., \& Cho, Y. B. (2011). Diastema closure with direct composite: architectural gingival contouring. Journal of Korean Academy of Conservative Dentistry, 36(6), 515-520.

7. da Cunha, L. F., Valeretto, T. M., Pirolo, R., Mondelli, J., Gonzaga, C. C., \& Furuse, A. Y. (2012). Free-hand stratification with composite resins for the closure of anterior diastema. $R S B O$ Revista Sul-Brasileira de Odontologia, 9(3), 334339.

8. Magne, P., \& Belser, U. (2003). Bonded porcelain restorations in the anterior dentition: a biomimetic approach. 1e éd. Chicago; 140-5; Quintessence Books.

9. Gordan, V. V., Shen, C., Riley III, J., \& Mjör, I. A. (2006). Two-year clinical evaluation of repair versus replacement of composite restorations. Journal of Esthetic and Restorative Dentistry, 18(3), 144-153.

10. Hussain, U., Ayub, A., \& Farhan, M. (2013). Etiology and treatment of midline diastema: A review of literature. Pakistan orthodontic journal, 5(1), 27-33.

11. Henston, D. S., Kumaraswamy, B. N., \& Subhash, C. (2012). Closure of diastema by composite resin. Dental Impact. 4(1):53-55. 